\title{
A model of the confidence channel of fiscal policy*
}

\author{
Bernardo Guimaraes $^{\dagger} \quad$ Caio Machado Marcel Ribeiro $^{\ddagger}$
}

July 2014

\begin{abstract}
This paper presents a simple macroeconomic model where government spending affects aggregate demand directly and indirectly, through an expectational channel. Prices are fully flexible and the model is static, so intertemporal issues play no role. There are three important elements in the model: (i) fixed adjustment costs for investment; (ii) noisy idiosyncratic information about the economy; and (iii) imperfect substitution among private goods and goods provided by the government. An increase in government spending raises the demand for private goods and raises firms' expectations about what others will be producing and demanding. The optimal level of government expenditure is larger when the desired level of investment is small, which we interpret as times of low economic activity.

KEYWORDS: fiscal policy, confidence, expectations, fiscal multiplier, aggregate demand.

Jel Classification: E32, E62
\end{abstract}

\section{Introduction}

There is a widespread perception among policy makers, the business community and the media that governments should intervene to induce confidence in the economy. However, this 'confidence channel' is met with skepticism among economists owing to the lack of theoretical backing. Mankiw (2009) is sympathetic to the view that "confidence is the key to getting the economy back on track", but adds that "we economists don't know very much about what drives the animal spirits of economic participants. Until we figure it out, it is best to be suspicious of any policy whose benefits are supposed to work through the amorphous channel of confidence". Kotlikoff (2012) discusses the possibility that "thanks to the government's intervention, the economy will psyche itself up, coordinate on good times, produce good times" and adds that "the coordination failure models do contain this magic as a real possibility", but asks "how, precisely, can the government coordinate beliefs on good times?" Cochrane (2009) complains that commentators "say that we should have a fiscal stimulus to 'give people confidence' even if we have neither theory nor evidence that it will work".

\footnotetext{
${ }^{*}$ We thank Luis Araujo, Braz Camargo, Fabio Kanczuk, and seminar participants at the Sao Paulo School of Economics for helpful comments. Bernardo Guimaraes gratefully acknowledges financial support from CNPq. Caio Machado gratefully acknowledges financial support from FAPESP. Marcel Ribeiro gratefully acknowledges financial support from CAPES.

†Sao Paulo School of Economics - FGV.

¥Sao Paulo School of Economics - FGV.

$\S$ Sao Paulo School of Economics - FGV.
} 
This paper presents a simple model where fiscal policy affects agents' expectations about others' investment decisions and, consequently, about the demand for their own goods. We see agents' demand expectations as natural model counterparts for what is often meant by confidence in policy discussions. The model is simple and standard in many respects. Three ingredients are key for the results: (i) fixed adjustment costs for investment; (ii) noisy information about firms' productivity; and (iii) public goods as imperfect substitutes for private goods. The interaction of these three features of the model gives rise to the confidence channel of fiscal policy.

Firms produce differentiated goods and operate under monopolistic competition. Hence an increase in the production of a given variety increases the demand for other varieties in the economy, raising their prices. Fixed adjustment costs for investment generate an inaction region, since it is not worth paying the fixed costs if the desired level of investment is small. This gives rise to strategic complementarities: one's decision about paying the fixed cost for investing depends on her expectations about demand and, consequently, about whether others will choose to leave the inaction region as well.

Second, firms receive an idiosyncratic signal about the aggregate productivity level. This creates strategic uncertainty among firms and removes an undesirable feature of models with strategic complementarities and complete information, namely that firms know what others are doing in equilibrium. When deciding whether to invest or not, firms have to try to forecast what others will be doing - and hence to forecast the forecast of others.

In equilibrium, different outcomes can be achieved as two regimes of a unique threshold equilibrium. For some parameters, coordination failures in investment arise: firms do not invest because they expect others to be stuck in the inaction region, even though it would be optimal for everyone to invest if they believed others would do so as well. The private sector fails to achieve the optimal level of aggregate demand owing to pessimistic beliefs a justified lack of "confidence".

The third important feature of the model is that fiscal policy has a direct effect on incentives for investment. In the model, goods provided by the government and those produced by private agents are imperfect substitutes - the CES aggregator treats them in the same way. Hence a larger level of government spending increases the utility from consumption of private goods in a way that resembles a preference shock in standard macroeconomic models. In consequence, larger government spending leads to a larger demand for private goods. The larger expected demand increases incentives for producers to incur the fixed cost and invest. The knowledge that others are thinking in the same way boosts market expectations - or "confidence". 1

The model is static for analytical convenience but captures some essential features of

\footnotetext{
${ }^{1}$ Fiscal policy might affect incentives for investment for other reasons, for example, government spending in could increase productivity in the private sector. We present one alternative model of this direct effect of fiscal policy in the appendix and show that an indirect effect through expectations is present as well.
} 
the economy that would also be present in a fully fledged dynamic framework. Firms are endowed with some initial level of capital, that can be interpreted as the level of capital inherited from previous periods, after depreciation has taken its toll. Usually, firms would invest because both capital has depreciated and productivity has increased. However, when the desired level of investment is low enough, firms might choose inaction - which is free instead of investment. Hence coordination failures arise in the model when the desired level of investment is low, which we interpret as times of low economic activity. ${ }^{2}$

Empirical work highlights the importance of non-convex adjustment costs for firms' decisions. Cooper and Haltiwanger (2006) build a structural model that incorporates convex and non-convex adjustment costs and use micro-level data on investment in the US in order to understand which kind of adjustment costs are needed to explain firms' behavior. They show that fixed adjustment costs are important for explaining investment decisions, which is consistent with one of our main assumptions.

Non-convex adjustment costs generate a region of inaction that is key for the results of this paper. Bloom (2009) uses micro level data to understand the effect of shocks to macroeconomic uncertainty on firms' decisions. He finds evidence for substantial nonconvex capital adjustment costs and shows the region of inaction plays a key role in explaining the reaction of firms to uncertainty shocks. In our model, fiscal policy can affect this region of inaction.

There are also empirical results supporting the confidence channel of fiscal policy. Bachmann and Sims (2012) employ a non-linear VAR using three variables: output, government expenditure and a measure of confidence. ${ }^{3}$ Their main finding is that government expenditure has larger impacts on output during recessions than in expansions. Moreover, when the confidence channel is shut down in their VAR, impulse responses in recessions become very similar to their counterparts in expansions. Their findings resonate with the results in this paper. Here, in periods where productivity is relatively low so that coordination failures might lead to inaction (recessions), government spending has a positive effect on agents' expected demand (confidence), but this effect is not present when everybody is confident others will be choosing a positive level of investment (booms).

The remainder of this introduction explores the relation between this paper and the literature. Next section presents the model, Section 3 shows the results and Section 4 concludes.

\section{$1.1 \quad$ Related literature}

In our model, as in Kiyotaki (1988), monopolistic competition induces strategic complementarities among firms because an increase in the production of a given variety increases the

\footnotetext{
${ }^{2}$ The static framework also makes clear that fiscal policy is not operating in the model through channels that rely on intertemporal considerations.

${ }^{3}$ The confidence measure is the Index of Consumer Expectations from Michigan Survey of Consumers.
} 
demand for other varieties in the economy, raising their prices. The assumption of a fixed cost generates increasing returns to scale in a region of the production function, but eventually an extra unit of output becomes increasingly costly. ${ }^{4}$ In Kiyotaki (1988), that gives rise to multiple equilibria. In a similar vein, Cooper and John (1988) show how strategic complementarities lead to multiple Pareto-ranked equilibria and Farmer and Guo (1994) explore similar ideas in a infinite-horizon framework. ${ }^{5}$

Since Keynes, it has been argued that investment decisions might be driven by "animal spirits", i.e., shifts in expectations for no apparent reason. A key question though is about whether, how and when policy interventions could affect demand and lead agents to coordinate in a good equilibrium. Models with multiple equilibrium do not allow us to understand what drives beliefs (as long as there are multiple equilibrium, beliefs about which one will be played are not pinned down by the model).

There is a growing literature focused on the role of noisy information in business cycles in a framework with imperfect common knowledge. In Woodford (2002) and Nimark (2008), noisy information leads to inertia in pricing decisions, which is particularly relevant for monetary policy. ${ }^{6}$ Closer to this paper, the models in Lorenzoni (2009), Angeletos and La'O (2010) and Angeletos and La'O (2013) aim at incorporating "demand shocks" and "sentiments" in a standard macroeconomic framework. In Chamley (2012), a preference (demand) shock might lead firms to choose a less efficient but flexible technology (which can be interpreted as inaction). In Guimaraes and Machado (2013), there is complete information but owing to timing frictions in investment decisions, expected demand plays a key role. None of those models study how government spending might affect confidence or sentiments.

Much of this literature considers models with weak complementarities, where the equilibrium is unique no matter the structure of information (see Morris and Shin (2002) and Angeletos and Pavan (2004)). Here, in contrast, the fixed adjustment costs imply strong complementarities in investment decisions. From a technical point of view, our model builds on the global game literature started by the seminal papers of Carlsson and Van Damme (1993) and Morris and Shin (1998). ${ }^{7}$ In this sense, the paper is related to Sákovics and Steiner (2012), who study who should benefit from subsidies in an economy with heterogeneous agents and strategic complementarities.

The paper is also related to a strand of the literature focused on the effects of fiscal policy in economic activity. ${ }^{8}$ In standard real business cycle models, government spending

\footnotetext{
${ }^{4}$ The specific assumptions on production are different in both models: here there are fixed costs for investment but a technology with decreasing returns, while in Kiyotaki (1988) there are increasing returns to capital and labour, but a maximum level of labour.

${ }^{5}$ See also Benhabib and Farmer (1994) and the survey in Benhabib and Farmer (1999). Multiple equilibria also arise in Gali (1996) and Ball and Romer (1991) but for different reasons.

${ }^{6}$ See also Adam (2007).

${ }^{7}$ Morris and Shin (2003) provides a comprehensive review of this literature.

${ }^{8}$ See, for instance, Rotemberg and Woodford (1992), Blanchard and Perotti (2002). For a survey of the results and new evidence, see Ramey (2011). For evidence considering several different countries, see Ilzetzki et al. (2013).
} 
generates a negative wealth effect that brings down household's income and induces them to work more. However, the size of government expenditure multipliers is likely to be low. Bouakez and Rebei (2007) build an RBC model with competitive firms where goods provided by the government and private goods are imperfect complements, and obtain results that are closer to VAR evidence on the relation between consumption and government expenditures.

In New Keynesian models with nominal rigidities, government spending has a positive effect on output, but in general the fiscal multiplier is way below one. As pointed by Linnemann and Schabert (2003), the effect of fiscal policy depends on monetary policy as the demand channel depends crucially on the real interest rate. Building on this insight, a recent literature emphasizes how fiscal multipliers can be large when the economy is in a liquidity trap. As argued in Christiano et al. (2011), if the economy is stuck at the zero lower bound, an increase in government spending can lead to an increase in expected inflation, which in turn helps to lower the real interest rate, boosting private spending (see also Eggertsson (2011) and Woodford (2011)). In Eggertsson and Krugman (2012), Ricardian equivalence does not hold because some agents are facing their borrowing limit. Moreover, due to an increase in prices, government spending can reduce the debt burden for credit constrained agents. Hence fiscal policy can be effective if a debt crisis pushes the economy against the zero lower bound. Erceg and Lindé (2014) show that once one we take into account that fiscal policy affects the duration of a liquidity trap, we get that the multiplier decreases with the amount of government spending. Mertens and Ravn (2014) argue that the effect of government spending on output is high only if the economy got at the ZLB because of a fundamental shock and not due to pessimistic expectations.

Those papers show that fiscal policy can be effective when the economy is against the zero lower bound, but have not much to say about economies that are far away from the zero lower bound - which was the case of many emerging economies during the last recession. Our model provides a different reason for why multipliers might be large which is not related to any kind of nominal rigidity (prices are perfectly flexible) and has nothing to do with the zero lower bound. The fiscal multiplier can be large in our model even though all the burden from taxation falls in the current period.

One objection to the demand channel emphasized by New-Keynesian models is that governments widely announce stimulus packages and spending plans. If sticky prices were the key reason for the effects of fiscal policy, governments should not make announcements, as they would only reduce the likelihood of firms being "surprised" by the policy, and thus could only lower the impact of policy. Here, in contrast, the main channel is an expectational one, and it makes perfect sense that governments announce they are increasing expenditure in order to boost demand expectations. 


\section{Model}

\subsection{Households}

There is a representative household who derives utility from leisure and from the consumption of private and public goods. His preferences are given by

$$
U=u\left(C_{p}, G\right)-\chi L
$$

where $\chi>0, L$ is the total amount of labour supplied, and utility from consumption depends on the amount of private and public goods consumed according to

$$
u\left(C_{p}, G\right)=\left(\omega C_{p}^{\frac{\theta-1}{\theta}}+(1-\omega) G^{\frac{\theta-1}{\theta}}\right)^{\frac{\theta}{\theta-1}}
$$

where $G$ is the amount of public goods, $\omega \in(0,1), \theta>1$ represents the elasticity of substitution between private and public goods and

$$
C_{p}=\left(\int_{0}^{1} c_{i}^{\frac{\theta-1}{\theta}} d i\right)^{\frac{\theta}{\theta-1}}
$$

where $c_{i}$ denotes the amount consumed of good $i$ and $\theta>1$ is the elasticity of substitution among private goods. ${ }^{9}$

The expression in (2) shows the first departure from standard macroeconomic models: the good provided by the government and private goods enter the consumer's utility function in the same way. Consumption aggregators of macroeconomic models usually comprise all types of goods from oranges to mobile phones, here parks are also combined in the CES aggregator. The elasticity of substitution $\theta>1$ between private goods is equal to the elasticity of substitution between a private good and the public good $G .{ }^{10}$

We call $G$ public goods, but they do not need to be non-rival and non-excludable. Strictly speaking, $G$ is the good provided by the government and it plays no special role in agents' utility function. It does not matter whether the government provides oranges, parks or TVs to the public.

The household buys private goods from firms while public goods are provided by the government and financed through a lump-sum tax on the representative household. Therefore, the household budget constraint is given by

$$
\int_{0}^{1} c_{i} p_{i} d i=w L+\Pi-T
$$

where $w$ is the wage, $\Pi$ is the amount of profits received from firms, $p_{i}$ is the price of good

\footnotetext{
${ }^{9}$ The assumption of linear utility on labour is similar to the one in Kiyotaki (1988) and implies a constant ratio between the wage and the hedonic price of the consumption aggregator.

${ }^{10}$ This assumption simplifies the exposition but is not needed for the main results of the paper.
} 
$i$ and $T$ are lump-sum taxes. We define the price index as

$$
P_{p}=\left(\int_{0}^{1} p_{i}^{1-\theta} d i\right)^{\frac{1}{1-\theta}}
$$

which turns out to be the minimal amount of spending needed to get one unit of the composite private good $C_{p}$. Therefore we can replace $\int_{0}^{1} c_{i} p_{i} d i=P_{p} C_{p}$ in the household budget constraint.

The total amount of labour supplied is given by:

$$
L=L_{K}+L_{G}+\int_{0}^{1} l_{i} d i
$$

where $L_{K}$ is the amount of labour supplied to capital producers, $L_{G}$ is the amount supplied to the government and $l_{i}$ is the amount supplied to firm $i$.

\section{$2.2 \quad$ Private goods firms}

There is a continuum of firms indexed by $i \in(0,1)$ that produces private goods consumed by the household. Each intermediate good $y_{i}$ is produced by a monopolist with the following technology:

$$
y_{i}=A k_{i}^{\alpha_{k}} l_{i}^{\alpha_{l}}
$$

where $A$ is a productivity shifter that is the same for every firm; $k_{i}$ and $l_{i}$ denote the amount of capital and labour used by firm $i$ and $\alpha=\alpha_{k}+\alpha_{l}<1$, so production is subject to decreasing returns. ${ }^{11}$

Firms are endowed with a level of capital $k_{0}>0$, which is the same across firms. Although the model is static, we think of $k_{0}$ as the level of capital firms inherited from a previous period, after depreciation has been considered. The level of capital is given by:

$$
k_{i}=k_{0}+I_{i}
$$

Firm's profits are given by

$$
\pi_{i}=p_{i} y_{i}-w l_{i}-P_{K} \mathcal{C}\left(I_{i}\right)
$$

where $P_{K}$ is the price of capital, $\mathcal{C}(\cdot)$ is a function that denotes the cost of investment, and $I_{i}$ denotes the amount of investment of firm $i$. A Firm maximizes households' valuation of its profit, given by real profits times the marginal utility of consuming one extra unit of the composite good, i.e., $\frac{\pi_{i}}{P_{p}} \frac{\partial C}{\partial C_{p}}$.

\footnotetext{
${ }^{11}$ The assumption of decreasing returns in production is a simple way of capturing the idea that at some point increasing output becomes increasingly costly. It is equivalent to assuming a production function with constant returns to scale and a third factor, say the knowledge about the production of that good, that is fixed.
} 
We assume that there are fixed costs of investing, so that $\mathcal{C}(\cdot)$ takes the form

$$
\mathcal{C}(I)= \begin{cases}I+\psi & \text { if } I>0 \\ 0 & \text { if } I=0\end{cases}
$$

where $\psi>0$ are the fixed cost associated with a positive level of investment. For simplicity, we impose irreversibility of capital, that is, $I_{i} \geq 0 \forall i \in[0,1]$.

This is the second important departure from a standard macroeconomic model. The fixed cost introduces locally increasing returns that may lead to strategic complementarities in investment decisions. But for a large enough level of production, there are decreasing returns.

Prices are fully flexible. Intermediate good firms choose the amount of labour they hire and the amount of capital they buy. The decision on capital can be decomposed in two choices: a firm chooses whether to pay the fixed cost and if yes, the amount of capital $k_{i}$. Henceforth "investing" and "paying the fixed cost for investing" will be used interchangeably.

\subsection{Capital goods firm}

There is a competitive representative firm producing a capital good. The production function is given by

$$
K=\frac{1}{\kappa} L_{K},
$$

where $\kappa>0$. Zero profit for capital producers implies that the price of the capital good is given by

$$
P_{K}=\kappa w
$$

\subsection{The government}

The government has access to a linear technology that transforms labour in the public good $G$, so that

$$
G=\frac{1}{\gamma} L_{G}
$$

where $\gamma>0$ and $L_{G}$ is the amount of labour hired by the government. Naturally, the government has to run a balanced budget, hence $T=w L_{G}$, where $w$ is the equilibrium wage. Therefore, additional household income from working to the government are compensated with higher lump-sum taxes. The level of government spending $G$ is chosen in order to maximize the expected utility of the household.

We make the following assumption to guarantee that the planner's problem has a solution:

$$
(1-\omega)^{\frac{\theta}{\theta-1}}<\gamma \chi
$$




\subsection{Information and Timing}

The only source of uncertainty in the model is the productivity factor $A$. Agents and the government have a prior over $A$ with pdf $f(\cdot)$. Each firm $i$ receives a signal

$$
x_{i}=\log A+\sigma \varepsilon_{i}
$$

where $\varepsilon_{i}$ is a random variable with pdf $q(\cdot)$ (with support in the real line) and $\mathbb{E}\left(\varepsilon_{i}\right)=0$. We will study the case $\sigma \rightarrow 0$. That removes fundamental uncertainty from the model, but does not remove strategic uncertainty. ${ }^{12}$

Heterogeneous information about $A$ implies that the value of $A$ and, more importantly, the action of others are not common knowledge, hence agents try to forecast what others will do. That is the third important feature of the model. Expectations about others' level of investment, and thus expectations about demand for producers' goods, are endogenously determined by the model. We believe those expectations capture the meaning of confidence in the discussions of Mankiw (2009), Cochrane (2009), Kotlikoff (2012) and others.

The timing of the model is the following:

1. Based on the prior information about $A$, the government chooses its expenditure $G$.

2. Firms receive their private signals and decide whether or not to pay the fixed cost of investing.

3. Firms choose their desired level of production and markets clear. ${ }^{13}$

The assumption that government expenditures are decided first captures the institutional frictions that prevents fiscal policy from reacting quickly to new information. ${ }^{14}$

\section{Equilibrium}

We start by solving the model at the third stage. We find the optimal decisions of firms and households taking choices about paying the fixed cost and government spending as given. We then solve the problem of firms in the second stage about paying the fixed cost. Last, we find the optimal level of government spending.

\footnotetext{
${ }^{12}$ See Morris and Shin (2003).

${ }^{13}$ For expositional simplicity, we assume that $A$ is observed at this stage, but owing to the assumption of very small $\sigma$, this assumption has no effect on the results.

${ }^{14}$ The assumption is in line with the VAR literature on government expenditure effects which builds on Blanchard and Perotti (2002). The usual assumption is that government expenditure shocks do not respond to contemporaneous shocks to other variables introduced in VAR specification.
} 


\subsection{Firms and household decisions}

The first-order conditions for the household's problem yield:

$$
\frac{\partial u}{\partial C_{p}}=\lambda P_{p}
$$

and

$$
\chi=\lambda w
$$

where $\lambda$ is a lagrange multiplier. Hence the real wage $w / P_{p}$ is given by

$$
\frac{w}{P_{p}}=\frac{\chi}{\frac{\partial C}{\partial C_{p}}}
$$

Now we must find the demand for each private good. Given a level of consumption $C_{p}$, cost minimization by the household implies

$$
p_{i}=y_{i}^{-\frac{1}{\theta}}\left(C_{p}\right)^{\frac{1}{\theta}} P_{p}
$$

Thus real profits can be written as

$$
\frac{\pi_{i}}{P_{p}}=\left(A k_{i}^{\alpha_{k}} l_{i}^{\alpha_{l}}\right)^{\frac{\theta-1}{\theta}} C_{p}^{\frac{1}{\theta}}-\frac{w}{P_{p}} l_{i}-\frac{P_{K}}{P_{p}} \mathcal{C}(i)
$$

Defining

$$
Y \equiv\left(\omega C_{p}^{\frac{\theta-1}{\theta}}+(1-\omega) G^{\frac{\theta-1}{\theta}}\right)^{\frac{\theta}{\theta-1}}
$$

and using (6) and (8) we can write real profits as

$$
\frac{\pi_{i}}{P_{p}}=C_{p}^{\frac{1}{\theta}}\left(\left(A k_{i}^{\alpha_{k}} l_{i}^{\alpha_{l}}\right)^{\frac{\theta-1}{\theta}}-\frac{\chi}{\omega} Y^{-\frac{1}{\theta}}\left(\kappa \mathcal{C}(i)+l_{i}\right)\right)
$$

A firm that paid the fixed cost of investing will be able to choose labour and capital. Taking first order conditions with respect to labour and capital from (9), ${ }^{15}$

$$
\left(\frac{\theta-1}{\theta}\right)\left(A k_{i}^{\alpha_{k}} l_{i}^{\alpha_{l}}\right)^{-\frac{1}{\theta}} \alpha_{k} k_{i}^{\alpha_{k}-1} A l_{i}^{\alpha_{l}}=\frac{\chi \kappa}{\omega} Y^{-\frac{1}{\theta}}
$$

and

$$
\left(\frac{\theta-1}{\theta}\right)\left(A k_{i}^{\alpha_{k}} l_{i}^{\alpha_{l}}\right)^{-\frac{1}{\theta}} \alpha_{l} l_{i}^{\alpha_{l}-1} A k_{i}^{\alpha_{k}}=\frac{\chi}{\omega} Y^{-\frac{1}{\theta}}
$$

Using (10) and (11), we find that $l_{i}=\kappa k_{i}\left(\alpha_{l} / \alpha_{k}\right)$. Replacing this in (10) yields the capital and labour choices of firms that are able to invest, denoted by $k_{H}(Y)$ and $l_{H}(Y)$ :

$$
k_{H}(Y, A)=\max \left\{X A^{(\theta-1) \eta} Y^{\eta}, k_{0}\right\}
$$

\footnotetext{
${ }^{15}$ The firm maximizes $\partial C / \partial C_{p}$ times real profits, but the term $\partial C / \partial C_{p}$ is a constant that can be ignored at this stage.
} 
and

$$
l_{H}(Y, A)= \begin{cases}\kappa\left(\frac{\alpha_{l}}{\alpha_{k}}\right) X A^{(\theta-1) \eta} Y^{\eta} & \text { if } k_{H}(Y, A) \geq k_{0} \\ l_{L}(Y) & \text { otherwise }\end{cases}
$$

where $X \equiv\left[\frac{\alpha_{k} \omega}{\chi \kappa}\left(\frac{\theta-1}{\theta}\right)\right]^{\theta \eta}\left[\kappa\left(\frac{\alpha_{l}}{\alpha_{k}}\right)\right]^{\eta \alpha_{l}(\theta-1)}>0$ and $\eta \equiv \frac{1}{\left(1-\alpha_{l}-\alpha_{k}\right) \theta+\alpha_{l}+\alpha_{k}} \in(0,1)$.

Firms that did not pay the fixed cost cannot adjust their capital level. They choose labour to satisfy (11) with $k_{i}=k_{0}$. Thus

$$
l_{L}(Y, A)=Z k_{0}^{\alpha_{k}(\theta-1) \varphi} A^{(\theta-1) \varphi} Y^{\varphi}
$$

where $Z \equiv\left[\frac{\omega}{\chi}\left(\frac{\theta-1}{\theta}\right) \alpha_{L}\right]^{\theta \varphi}>0$ and $\varphi \equiv \frac{1}{\alpha_{l}+\left(1-\alpha_{l}\right) \theta} \in(0,1)$.

Finally we can specify how much investing and non-investing firms will produce:

$$
y_{H}(Y, A)= \begin{cases}\left(\kappa\left(\frac{\alpha_{l}}{\alpha_{k}}\right)\right)^{\alpha_{l}} X^{\alpha} A^{\theta \eta} Y^{\alpha \eta} & \text { if } k_{H}(Y) \geq k_{0} \\ y_{L}(Y, A) & \text { otherwise }\end{cases}
$$

and

$$
y_{L}(Y, A)=Z^{\alpha_{l}} k_{0}^{\alpha_{l} \alpha_{k}(\theta-1) \varphi+\alpha_{k}} A^{\theta \varphi} Y^{\alpha_{l} \varphi}
$$

The payoffs of each type of firm are

$$
\hat{\pi}_{H}(Y, A) \equiv \frac{\pi_{H}}{P_{p}} \frac{\partial Y}{\partial Y_{p}}=\omega y_{H}(Y, A)^{\frac{\theta-1}{\theta}} Y^{\frac{1}{\theta}}-\chi\left(\kappa\left(k_{H}(Y, A)-k_{0}+\psi\right)+l_{H}(Y, A)\right)
$$

and

$$
\hat{\pi}_{L}(Y, A) \equiv \frac{\pi_{L}}{P_{p}} \frac{\partial Y}{\partial Y_{p}}=\omega y_{L}(Y, A)^{\frac{\theta-1}{\theta}} Y^{\frac{1}{\theta}}-\chi l_{L}(Y, A)
$$

The only endogenous variable in the expressions for firms' profit, labour and capital choices is $Y$. Both $\hat{\pi}_{H}(Y, A)$ and $\hat{\pi}_{L}(Y, A)$ are increasing functions of $Y$, for suppose $Y$ increases by $\Delta>0$ units: firms could simply not adjust their capital and labour and profits would still increase, as one can verify by inspection of (15) and (16). Adjusting one or both factors can only lead to larger profits.

We have to show there is an unique $Y$ consistent with firms' best responses. More specifically, we will show that the following equation has an unique solution:

$$
Y=\left(\omega C_{p}^{\frac{\theta-1}{\theta}}+(1-\omega) G^{\frac{\theta-1}{\theta}}\right)^{\frac{\theta}{\theta-1}}
$$

where

$$
C_{p}=\left(h y_{H}(Y, A)^{\frac{\theta-1}{\theta}}+(1-h) y_{L}(Y, A)^{\frac{\theta-1}{\theta}}\right)^{\frac{\theta}{\theta-1}}
$$

Next lemma proves and derives some properties of $Y$ in equilibrium. All proofs omitted from the text are in the appendix. 
Lemma 1. Equation (17) has an unique solution. In equilibrium, $Y$ is an increasing function of $G, A$ and $h$.

Not surprisingly, aggregate output is increasing in the productivity level, in government expenditure in public goods and in the proportion of firms that are investing, keeping fixed the other variables. A larger $A$ means firms will both choose a larger level of inputs and produce more with their inputs; a larger $h$ means a larger fraction of firms will invest; and an increase in the supply of public goods $G$ affects output directly (equation 17) and also indirectly, since a large $Y$ affects the choices of producers and leads to a larger $C_{p}$. The fact that government spending increases $Y$ does not imply that a larger level of $G$ increases welfare because the production of $G$ requires taxing agents to pay for the labour costs of government spending (or analogously, requires that agents work more).

Last, it is useful to pin down the amount of labour supplied given $h, A$ and $G$ in equilibrium. The amount of labour supplied to the government is simply $L_{g}(G)=\gamma G$. The amount of labour supplied to capital goods firms is

$$
L_{K}(h, A, G)=\kappa h\left(\psi+k_{H}(Y(h, A, G))-k_{0}\right) .
$$

The amount of labour supplied to private goods firms is

$$
L_{P}(h, A, G)=h l_{H}(Y(h, A, G), A)+(1-h) l_{L}(Y(h, A, G), A) .
$$

We write $L(h, A, G)=L_{g}(G)+L_{K}(h, A, G)+L_{P}(h, A, G)$.

\subsection{The investment game}

Let $D(Y, A)$ denote the difference in payoffs between firms that are investing and not investing:

$$
D(Y, A)=\hat{\pi}_{H}(Y, A)-\hat{\pi}_{L}(Y, A)
$$

Proposition 1 shows that firms that can adjust their capital level benefit more from an increase in $Y$ than firms that can not. This result is important for the supermodularity of the investment game in the second stage of the model and for the optimal choice of government spending in the first stage.

Proposition 1. $D(Y, A)$ is an increasing function of $Y$ and $A$.

Proposition 1 shows the incentive to pay the fixed cost of investment depends on (i) productivity and (ii) demand. The effect of $A$ on $D(Y, A)$ captures the supply-side incentives for investment. A larger $A$ leads to a larger desirable level of capital and higher profits to investing.

Figure 1 shows that when aggregate demand is $Y_{0}$, profits of non-investing firms are larger than profits of investing firms and the difference is $\chi \kappa \psi$. At $Y_{0}$, the optimal level of 


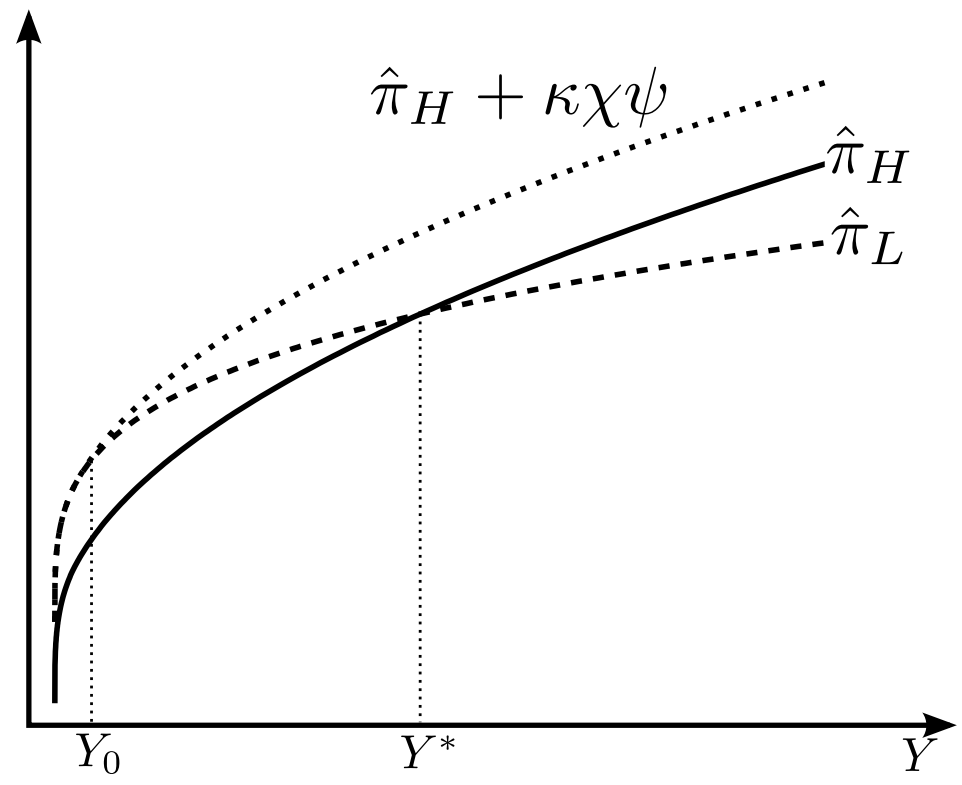

Figure 1: Complementarities

investment in the absence of the fixed cost would be zero, so it is never optimal to pay the fixed cost. The relative profitability of investing $D(Y, A)$ is increasing in $Y$, a larger level of aggregate demand leads to higher profits and stronger incentives to invest. Intuitively, investing firms are able to fully take advantage of the large demand because they can adjust both inputs. For large enough aggregate demand $\left(Y \geq Y^{*}\right)$, firms find it optimal to incur the fixed costs of investment.

The next corollary comes directly from Proposition 1 and from $Y(h, A, G)$ being increasing in all arguments (Lemma 1).

Corollary 1. Let $\hat{D}(h, A, G) \equiv D(Y(h, A, G), A) . \hat{D}(\cdot)$ is increasing in all arguments.

One implication of Proposition 1 and its corollary is that agents' decisions about investing or not are strategic complements. Incentives for investing depend positively on $Y$, which in turn depends on others' investment decisions. Another implication is that a higher level of government expenditure in public goods also leads to a larger demand and hence larger incentives for investment as well.

In case of complete information, the model would display multiple equilibria in a range of parameters. ${ }^{16}$ The following proposition shows there is a unique equilibrium in the model. ${ }^{17}$

Proposition 2. For any $\delta>0$ there is a sufficiently small $\sigma$ such that in every strategy that survives iterated deletion of strictly dominated strategies, firms pay the fixed cost whenever $x_{i}>A^{*}(G)+\delta$ and do not pay the fixed cost whenever $x_{i}<A^{*}(G)-\delta$. The threshold $A^{*}(G)$

\footnotetext{
${ }^{16}$ See Appendix A.

${ }^{17}$ The model has multiple possible outcomes as Benhabib and Farmer (1999) and others, but beliefs are pinned down by the model. The advantage of this approach is that we can understand how policies affect beliefs.
} 
is given by

$$
\int_{0}^{1} \hat{D}\left(h, A^{*}(G), G\right) d h=0,
$$

and $A^{*}(G)$ is a decreasing function of $G$.

The proof of the uniqueness result is a direct application of the Proposition 2.2 in Morris and Shin (2003). Since investment decisions are strategic complements (Corollary 1) and there is strategic uncertainty, firms need to form expectations about others' investment decisions $(h)$. Each firm understands that others' signals are likely to be similar to its own information and that all agents are trying to forecast what others will do. As well known in the literature of global games, that leads to a unique equilibrium.

The assumption of vanishing uncertainty $(\sigma \rightarrow 0)$ greatly simplifies finding a expression for the productivity threshold and ensures all firms make the same investing decision. The threshold determines two regimes: an investing regime in which all firms are investing (if $A \geq A^{*}(G), h=1$ ) and a non-investing regime (if $A<A^{*}(G), h=0$ ), as shown in Figure 2. Now consider a firm that got a signal $x_{i}$ equal to the productivity threshold $A^{*}(G)$. As discussed by Morris and Shin (2003), when $\sigma$ is sufficiently small, the posterior belief over other firms' investment in this pivotal circumstance converges to a uniform. The expression in $(20)$ shows $A^{*}(G)$ is the productivity level such that a firm is indifferent between investing or not in this pivotal contingency.

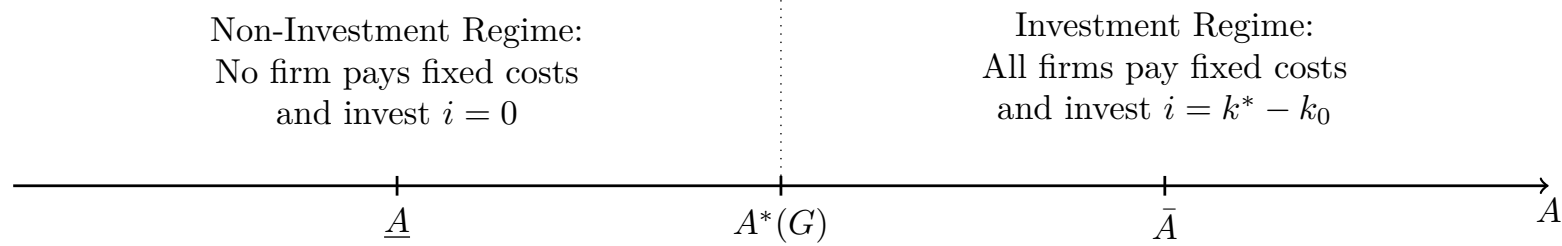

Figure 2: Threshold Equilibrium

Denote by $\bar{A}$ the productivity level such that it is optimal for an individual firm to invest regardless of others' decisions and $\underline{A}$ the productivity level such that it is optimal for an individual firm not to invest regardless of what others do. ${ }^{18}$ When $A>\bar{A}$, all firms choose to invest because the productivity level is high enough to persuade firms to incur the fixed adjustment cost regardless of others' decisions. When $A \in\left(A^{*}, \bar{A}\right)$, firms coordinate in the "good" outcome. Fundamentals are not strong enough to induce all firms to invest regardless of others, but are sufficiently high to induce firms to invest when beliefs that other firms will also do so are taken into account. For $A \in\left(\underline{A}, A^{*}\right)$, firms stay in the region of inaction due to a coordination failure. The economy gets stuck in the non-investment regime with a low level of economy activity even though it would be individually optimal for firms to invest

\footnotetext{
${ }^{18} \underline{A}$ and $\bar{A}$ are formally defined in Appendix A.
} 
if they were confident others would do so as well. Low expectations - lack of confidence leads to an inefficiently low level of investment. Finally, when $A<\underline{A}$, firms are choosing not to invest and would choose so even under optimistic beliefs.

An increase in government expenditure shifts down the productivity threshold for two reasons. First, there is a direct effect. An increase in government expenditure leads to a larger demand for private goods, which induces households to supply more labour and increases firms' incentives to invest. The role played by $G$ is similar to the role played by demand shocks in standard DSGE models.

Second, there is also an indirect effect through expectations, which we dub 'the confidence channel of fiscal policy'. Knowing other firms also face higher demand and are thus more likely to invest, a firm expects a larger demand for its own goods and hence is more likely to leave the inaction region. This confidence boost leads to a second order increase in confidence because firms know others' investment decisions depend on their expectations as well. Expectations over other firms' expectations about the aggregate demand also affect individual incentives for investment, so the confidence channel incorporates not only expectations but also higher-order expectations on investment decisions.

\subsection{Optimal fiscal policy}

Firms' market power leads to well known monopoly distortions. The fixed cost for investment might lead to coordination failures: firms would find optimal to pay the fixed cost and produce more if they expected others to do so, but might get stuck in the inaction region owing to pessimistic expectations. The optimal fiscal policy considers not only the direct benefit of provision of public goods but also its potential impact on those market failures.

The government chooses $G$ to maximize welfare of the representative household given its prior distribution over $A$ :

$V(G) \equiv \int_{0}^{A^{*}(G)}(Y(0, A, G)-\chi L(0, A, G)) f(A) d A+\int_{A^{*}(G)}^{\infty}(Y(1, A, G)-\chi L(1, A, G)) f(A) d A$

with

$$
L(0, A, G)=\gamma G+l_{L}(Y(0, A, G), A)
$$

and

$$
L(1, A, G)=\gamma G+l_{H}(Y(1, A, G), A)+\kappa\left(\psi+k_{H}(Y(1, A, G), A)-k_{0}\right)
$$

The flipside of a larger government spending is that the representative agent works more. Taking the first order condition with respect to $G$ we get that the solution to the planner's 
problem must satisfy

$$
\begin{aligned}
& \int_{0}^{A^{*}(G)}\left(\frac{\partial Y(0, A, G)}{\partial G}-\chi \frac{\partial L(0, A, G)}{\partial G}\right) f(A) d A+\int_{A^{*}(G)}^{\infty}\left(\frac{\partial Y(1, A, G)}{\partial G}-\chi \frac{\partial L(1, A, G)}{\partial G}\right) f(A) d A \\
& -\frac{\partial A^{*}(G)}{\partial G} f\left(A^{*}(G)\right)\left(\left[Y\left(1, A^{*}(G), G\right)-\chi L\left(1, A^{*}(G), G\right)\right]-\left[Y\left(0, A^{*}(G), G\right)-\chi L\left(0, A^{*}(G), G\right)\right]\right)=0
\end{aligned}
$$

The first and the second integrals correspond to the usual social planner's problem. The expected increase in households' utility through a larger provision of public goods has to compensate its opportunity cost, which is the disutility from labour. That effect is basically the same in both the non-investing regime and in the investment regime. Were this the only way through which government spending would affect welfare, fiscal policy would aim at equalizing the marginal benefit of public goods and its marginal cost.

However, in this economy, fiscal policy might be able to switch the economy from a noninvestment regime to an investment regime. That is the confidence channel and is reflected in the second line of the equation. Proposition 2 shows that $\frac{\partial A^{*}(G)}{\partial G}<0$, an increase in government spending reduces the threshold for investment. The second term $f\left(A^{*}(G)\right)$ is the prior probability that a marginal shift of the threshold will affect investment decisions. The last term multiplying this derivative is the welfare gain resulting from a switch to the investment regime. ${ }^{19}$

The second line of (21) thus represents the expected gains from a marginal increase in government spending owing to a regime switch. This channel is relevant when the prior probability of the economy coordinating in the no-investment regime is large. We interpret that as capturing times of recession, when firms might be willing to choose inaction over investment owing to an intrinsic bad state of the economy, which is fueled by low demand expectations.

In this situation, the provision of public goods with a marginal value below its cost can be welfare improving. By increasing demand for private goods and affecting expectations about others' investment decisions, the seemingly inefficient increase in government spending can inducing firms to leave the inaction zone and improve welfare in the economy. In other words, expansionary fiscal policy would increase firms' confidence on aggregate demand.

As an illustration, the financial crisis of 2008-9 can be interpreted as a negative shock to $A$ that reduces firms' productivity. Knowing the shock has affected all firms in the economy, an individual firm now expects lower demand for its goods. The low levels of productivity and demand reduce their desired level of investment. In the absence of the fixed adjustment cost, investment in the economy would be small, but positive. However, owing to the fixed costs, firms prefer inaction. In this scenario, an increase in government spending works as

\footnotetext{
${ }^{19}$ When $A=A^{*}(G)$, firms' payoffs are higher in the investment regime than in the non-investment regime (firms are indifferent under a uniform belief over $h$ ). In the investment regime, firms produce more, so for a given $G, \partial Y / \partial C_{p}$ is smaller, so real profits and real wages are higher. Hence welfare of the representative household must be higher in the investment regime when $A=A^{*}(G)$ and thus the gain from switching is positive.
} 
a demand shock, increasing households' demand for private goods. The optimal level of production for firms has increased and workers also find optimal to work more. Everyone knows others reason this way, and that might be enough to switch the economy to the investment regime.

The following proposition summarizes the results on optimal fiscal policy in this model.

Proposition 3. Optimal government spending is chosen to satisfy the condition in (21). At the optimal $G$, the marginal cost of providing public goods equates the expected direct marginal benefit plus the expected gains from shifting the economy from the bad to the good regime.

A corollary to Proposition 3 is that when the probability of a coordination failure is negligible, optimal fiscal policy equates its marginal cost and its expected direct marginal benefit. As shown in (21), fiscal policy should be more expansionary when the prior probability of a coordination failure at the margin $f\left(A^{*}(G)\right)$ is larger.

\section{Final remarks}

This paper proposes a model of the confidence channel of fiscal policy. Fixed adjustment costs for investment generate an inaction zone. Noisy idiosyncratic information about the economy generates strategic uncertainty. In this setup, variables that have a direct effect on incentives for investment also affect beliefs about whether other firms will leave the inaction zone. In particular, an increase in government expenditure that induces households to demand more private goods also raises expectations about investment by other firms. The effect on expectations provides further incentives for an individual firm to leave the inaction zone.

The paper shows the confidence channel of fiscal policy in a very simple setup that allows for analytical results. The drawback of this approach is that we cannot make quantitative statements. The study of this channel in a quantitative dynamic macroeconomic framework is left for future research.

\section{A The model with complete information}

In case $A$ is common knowledge, the economy may feature multiple equilibria. Figure 3 shows regions where both investing and not-investing are equilibria. $\underline{A}$ is the technology level that implies a single producer is indifferent between investing or not if everyone is investing, while $\bar{A}$ is the technology level that implies a single producer is indifferent between investing or not if everyone is choosing not to invest. $\underline{A}$ satisfies $\hat{D}(1, \underline{A}, G)=0$ and $\bar{A}$ satisfies $\hat{D}(0, \bar{A}, G)=0$. 


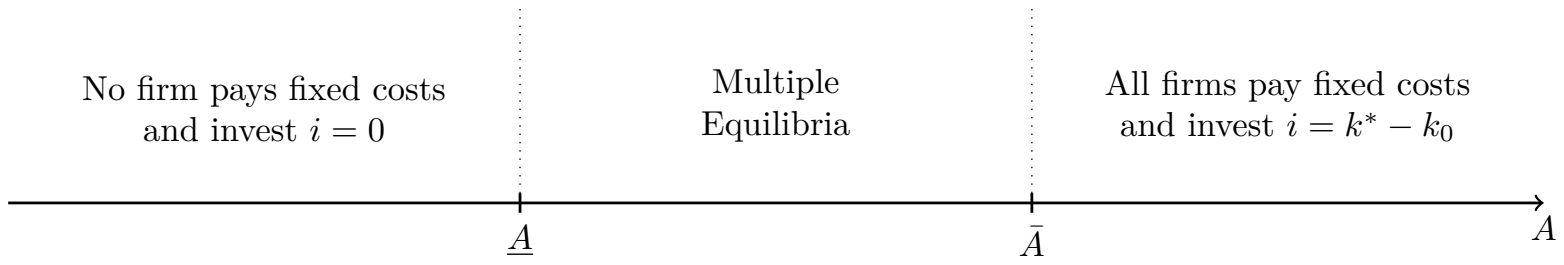

Figure 3: Multiple Equilibria

Since $\hat{D}(h, A, G)$ is increasing in $A$ and $h, \bar{A}>\underline{A}$. In the region satisfying $A>\bar{A}$, is is optimal to invest and there is only one possible outcome. Conversely, when $A<\underline{A}$, agents never invest in equilibrium. However, if $A \in(\underline{A}, \bar{A})$, there are multiple equilibria as individual investment decisions depend on (self-fulfilling) expectations about others' actions. Lemma 1 implies that both $\underline{A}$ and $\bar{A}$ are decreasing functions of $G$. Hence an increase in government spending affects the region where coordination failures could occur.

\section{B Productive Government Expenditure}

This section presents a variation of our model where government expenditures affect the productivity of firms instead of boosting demand for private goods. Household utility is now given by

$$
U=C_{p}-\chi L
$$

where $C_{p}$ is as defined in (3). The household budget constraint is the same as in the problem of Section 2.1.

The production function of each intermediate firm is now given by

$$
y_{i}=A g^{\alpha_{g}} k_{i}^{\alpha_{k}} l_{i}^{\alpha_{l}}
$$

where $\alpha_{g}+\alpha_{k}+\alpha_{l}<1$ and $g$ denotes the amount of public goods produced in this economy. Government expenditures affect the supply side of the economy by making firms more productive. This is a standard assumption when studying the effects of government expenditure since Barro (1990) and captures the positive effects of public services and infrastructure on productivity.

As in (2.4), government produces the public good according to a linear production function:

$$
g=\frac{1}{\gamma} L_{g}
$$

where $L_{g}$ is the amount of labor used by the government to produce the public good $g$.

Capital good firms technology is the same as in (2.3). The timing and the information structure of this model are the same as in Section 2 .

We can show that the amount consumed by the representative household in this economy 
is an increasing function of $g, A$ and $h$, as before. Specifically, for a given $g, A$ and $h$, we can write the household consumption as

$$
C_{p}(h, A, g)=Y\left(h, A g^{\alpha_{g}}, 0\right)
$$

where $Y(\cdot)$ refers to the equilibrium GDP in the model of Section 2. To see this, notice that, once government has announced a level of expenditure $g$, this model is essentially the same as the previous model if we set $G=0$ and set the productivity as $A g^{\alpha_{g}}{ }^{20}$. We will refer to $\hat{A}(g) \equiv A g^{\alpha_{g}}$ as the effective productivity from now on. The amount of labor supplied to the goverment is still given by $L_{g}(g)=\gamma g$ and the total amount of labor supplied to capital and private goods firms is now given by

$$
\hat{L}_{K}(h, A, g)=L_{K}\left(h, A g^{\alpha_{g}}, 0\right)
$$

and

$$
\hat{L}_{P}(h, A, g)=L_{P}\left(h, A g^{\alpha_{g}}, 0\right)
$$

where we use hats to denote the labor supplied to the private and capital goods firms in the equilibrium of this model and $L_{K}(\cdot)$ and $L_{P}(\cdot)$ are the same as in the previous model (see the expressions in (18) and (19)). As in Section 2, we define the total amount of labor supplied as $\hat{L}(h, A, g)=L_{g}(g)+\hat{L}_{K}(h, A, g)+\hat{L}_{P}(h, A, g)$.

Proposition 1 and its corollary still hold in this model, since this is just a special case of the previous model with no goverment expenditures and productivity replaced by its effective counterpart $\hat{A}(g)$. Thus, there are strategic complementarities and dominance regions as before, meaning that in equilibrium firms will decide whether or not to invest according to a threshold, denoted by $A^{* *}(g)$. But notice that the following relation must be satisfied

$$
A^{* *}(g)=A^{*}(0) g^{-\alpha_{g}}
$$

where $A^{*}(\cdot)$ is the threshold of the previous model. Therefore government expenditures bring the threshold down, increasing the probability of the high investment regime.

We can then show a result on optimal fiscal policy analogous to the one in Section 3.3. The government chooses $G$ to maximize

$V(g) \equiv \int_{0}^{A^{* *}(g)}\left(C_{p}(0, A, g)-\chi \hat{L}(0, A, g)\right) f(A) d A+\int_{A^{* *}(g)}^{\infty}\left(C_{p}(1, A, g)-\chi \hat{L}(1, A, g)\right) f(A) d A$

\footnotetext{
${ }^{20} G$ refers to the amount of government provision of public goods in the model of Section 2
} 
If an interior solutions, then it must satisfy the following first order condition

$$
\begin{aligned}
& \int_{0}^{A^{* *}(g)}\left(\frac{\partial C_{p}(0, A, g)}{\partial g}-\chi \frac{\partial \hat{L}(0, A, g)}{\partial g}\right) f(A) d A+\int_{A^{* *}(g)}^{\infty}\left(\frac{\partial C_{p}(1, A, g)}{\partial g}-\chi \frac{\partial \hat{L}(1, A, g)}{\partial g}\right) f(A) d A \\
- & \frac{\partial A^{* *}(g)}{\partial g} g\left(A^{* *}(g)\right)\left(\left[C_{p}\left(1, A^{* *}(g), g\right)-\chi \hat{L}\left(1, A^{* *}(g), g\right)\right]-\left[C_{p}\left(0, A^{* *}(g), g\right)-\chi \hat{L}\left(0, A^{* *}(g), g\right)\right]\right)=0
\end{aligned}
$$

As before, the first line of (23) represents the direct benefit of more government spending: effective productivity increases and firms produce before. The second line of (23) represents the expected gains from a marginal increase in government spending owing to a regime switch.

We now show that an interior solution exists, which implies that a result similar to Proposition 3 holds in this model. Clearly, $g=0$ is a not a solution here, since in that case firms produce nothing and households gets zero welfare. In order to show that an interior solution exists, it suffices to show that the increase in $C_{p}$ after an infinitesimal increase in $g$, goes to zero when $g \rightarrow \infty$ for $h=1$ and $h=0$. But given (22), this is equivalent to show that in the model of Section 2,

$$
\lim _{g \rightarrow \infty} \frac{\partial Y\left(h, A g^{\alpha_{g}}, 0\right)}{\partial g}=0
$$

for $h=1$ and $h=0$. Doing the algebra, one can see that when $h=0$ we can write $Y$ explicitly as $Y=C\left(A g^{\alpha_{g}}\right)^{\frac{1}{1-\alpha_{l}}}$ with $C>0$ and when $h=1$ we get $Y=D\left(A g^{\alpha_{g}}\right)^{\frac{1}{1-\alpha_{l}-\alpha_{k}}}$ with $D>0$. Since $\alpha_{g}+\alpha_{k}+\alpha_{l}<1$, the marginal effect of government spending on household consumption vanishes as $g$ goes to infinity while the desutility of labor of an additional unit of government spending is at least $\gamma \chi>0$.

\section{Proofs}

\section{Proof of Lemma 1}

First sentence: The LHS of (17) is just the 45 degree line. Notice that the RHS is larger than zero as long as $G>0$. Taking the derivative of the LHS with respect to $Y$ and doing some algebra yields

$$
\frac{\partial R H S}{\partial Y}=\omega\left[\left(h\left(\frac{y_{H}(Y, A)}{Y}\right)^{\frac{\theta-1}{\theta}} \varepsilon_{y_{H}}+(1-h)\left(\frac{y_{L}(Y, A)}{Y}\right)^{\frac{\theta-1}{\theta}} \varepsilon_{y_{L}}\right)\right]
$$

where $\varepsilon_{y_{H}} \equiv \frac{\partial y_{H}}{\partial Y} \frac{Y}{y_{H}}$ and $\varepsilon_{y_{L}} \equiv \frac{\partial y_{L}}{\partial Y} \frac{Y}{y_{L}}$. The expressions in (13) and (14) imply that those elasticities are constant. Moreover $\frac{y_{H}(Y, A)}{Y}$ and $\frac{y_{L}(Y, A)}{Y}$ are decreasing in $Y$ (the exponents of $Y$ in both functions $y_{H}$ and $y_{L}$ are smaller than one). Therefore, this derivative is decreasing in $Y$ and this function in concave. Now, as $Y \rightarrow \infty$, both $\frac{y_{H}(Y, A)}{Y}$ and $\frac{y_{L}(Y, A)}{Y}$ converge to 
zero, implying that $\frac{\partial R H S}{\partial Y}$ goes to zero as well and thus the RHS crosses the 45 degree line at some point. Since the RHS is concave, it cannot cross it more than once. Therefore, $Y$ is pinned down in equilibrium and we write it as $Y(h, A, G)$. In consequence, a unique $Y_{p}$ is pinned down in equilibrium as well.

Second sentence: Since $y_{H}(Y) \geq y_{L}(Y)$, the RHS of (17) increases in $h$. It follows that $Y(h, A, G)$ is increasing in $h$. Same reasoning applies to $G$ and $A$.

\section{Proof of Proposition 1}

We start by showing that $D(Y, A)$ is increasing in $Y$. Let $\Delta>0$ be a small variation in $Y$. We want to show that

$$
\hat{\pi}_{H}(Y+\Delta, A)-\hat{\pi}(Y, A) \geq \hat{\pi}_{L}(Y+\Delta, A)-\hat{\pi}_{L}(Y, A)
$$

Let $\tilde{\pi}_{H}$ be the profit from investing when output is $Y+\Delta$, and the firms follows the following strategy: it keeps the level of capital at $\tilde{k}_{H} \equiv k_{H}(Y, A)$ and optimally chooses labour so that $\tilde{l}_{H}$ satisfies (11) with $k_{i}$ replaced by $\tilde{k}_{H}$. Thus $\tilde{\pi}_{H}$ is a lower bound for $\hat{\pi}_{H}(Y+\Delta, A)$. Using (12) and (14), we can write

$$
\begin{gathered}
\tilde{l}_{H}=\left(\frac{\tilde{k}_{H}}{k_{0}}\right)^{\alpha_{k}(\theta-1) \varphi} l_{L}(Y+\Delta, A) \\
l_{H}(Y, A)=\left(\frac{\tilde{k}_{H}}{k_{0}}\right)^{\alpha_{k}(\theta-1) \varphi} l_{L}(Y, A) \\
\tilde{y}_{H}=\left(\frac{\tilde{k}_{H}}{k_{0}}\right)^{\alpha_{l} \alpha_{k}(\theta-1) \varphi+\alpha_{k}} y_{L}(Y+\Delta, A) \\
y_{H}(Y, A)=\left(\frac{\tilde{k}_{H}}{k_{0}}\right)^{\alpha_{l} \alpha_{k}(\theta-1) \varphi+\alpha_{k}} y_{L}(Y, A)
\end{gathered}
$$

After some algebra, we get:

$$
\begin{aligned}
\tilde{\pi}_{H}-\hat{\pi}_{H}(Y, A)=\left(\frac{\tilde{k}_{H}}{k_{0}}\right)^{\alpha_{k}(\theta-1) \varphi}[ & \omega\left((Y+\Delta)^{\frac{1}{\theta}} y_{L}(Y+\Delta, A)^{\frac{\theta-1}{\theta}}\right. \\
& \left.\left.\left.-Y^{\frac{1}{\theta}} y_{L}(Y, A)^{\frac{\theta-1}{\theta}}\right)\right)-\chi\left(l_{L}(Y+\Delta, A)-l_{L}(Y, A)\right)\right]
\end{aligned}
$$

and

$$
\begin{array}{r}
\hat{\pi}_{L}(Y+\Delta, A)-\hat{\pi}_{L}(Y, A)=\omega\left((Y+\Delta)^{\frac{1}{\theta}} y_{L}(Y+\Delta, A)^{\frac{\theta-1}{\theta}}-Y^{\frac{1}{\theta}} y_{L}(Y, A)^{\frac{\theta-1}{\theta}}\right) \\
-\chi\left(l_{L}(Y+\Delta, A)-l_{L}(Y, A)\right)
\end{array}
$$


Since $\tilde{k}_{H} \geq k_{0}$, one can verify that $\tilde{\pi}_{H}-\hat{\pi}_{H}(Y, A) \geq \hat{\pi}_{L}(Y+\Delta, A)-\hat{\pi}_{L}(Y, A)$. Since $\tilde{\pi}_{H}$ is a lower bound for $\hat{\pi}_{H}(Y+\Delta, A)$, it must be that $\hat{\pi}_{H}(Y+\Delta, A)-\hat{\pi}_{H}(Y, A) \geq \hat{\pi}_{L}(Y+\Delta, A)-$ $\hat{\pi}_{L}(Y, A)$.

The proof for $D(Y, A)$ increasing in $A$ is analogous.

\section{Proof of Proposition 2}

We just need to show that our investment game satisfies the assumptions in Morris and Shin (2003). We have already shown supermodularity in Corollary 1. We need to show there are dominance regions: for any given $G$ there must exist $\epsilon>0, \underline{A}$ and $\bar{A}$ such that $\hat{D}(h, \underline{A}, G)<-\epsilon$ and $\hat{D}(h, \bar{A}, G)>\epsilon$. To see this, notice that if $h=1$ there is a sufficiently low $\underline{A}$ such that $k_{H}(Y, \underline{A})=k_{L}(Y, \underline{A})$, implying that $\hat{D}(1, \underline{A}, G)=-\chi \psi$ (and therefore $\hat{D}(h, \underline{A}, G)<-\chi \psi$ for any $h \in[0,1])$. Finally, one can verify that $D(Y, A)$ is an unbounded function of $A$ for any $Y$.

The argument in Morris and Shin (2003) yields the expression in (20). The proof that $A^{*}(G)$ is decreasing in $G$ then comes directly from the fact $\hat{D}(\cdot)$ is increasing $G$, as shown in Corollary 1.

\section{Proof of Proposition 3}

We need to show that the planner's problem has an interior solution, so that the first order condition (21) characterizes the optimal level of $G$. The cost of an infinitesimal increase in $G$ is given by:

$$
\frac{\partial L}{\partial G}=\chi\left[\gamma+\frac{\partial Y}{\partial G}\left(h \frac{\partial l_{H}}{\partial Y}+(1-h) \frac{\partial l_{L}}{\partial Y}+h \kappa \frac{\partial k_{H}}{\partial Y}\right)\right],
$$

which is the amount of extra work imposed on the representative agent. The benefit is given by the increase in GDP $(\partial Y / \partial G)$. Therefore, the net benefit of an increase in government spending is given by

$$
\frac{\partial Y}{\partial G}\left[1-\chi\left(h \frac{\partial l_{H}}{\partial Y}+(1-h) \frac{\partial l_{L}}{\partial Y}+h \kappa \frac{\partial k_{H}}{\partial Y}\right)\right]-\chi \gamma
$$

We first show that as $G \rightarrow \infty$, the expression in (27) is negative. It suffices to show that that $\lim _{G \rightarrow \infty} \frac{\partial Y}{\partial G}<\chi \gamma$. If $h=0$ or $h=1$, we get $Y_{p} / Y=T_{i} Y^{-\xi_{i}} \equiv H(Y)$, where $T_{i}$ and $\xi_{i}$ are constants such that $T_{i}>0$ and $\xi_{i} \in(0,1)$, for $i \in\{L, H\}$. Using (17) yields an expression for $G$ as a function of $Y$ :

$$
G=\left[\frac{1}{1-\omega} Y^{\frac{\theta-1}{\theta}}\left(1-\omega(H(Y))^{\frac{\theta-1}{\theta}}\right)\right]^{\frac{\theta}{\theta-1}}
$$


Taking derivatives of $G$ with respect to $Y$ leads to

$$
\frac{\partial G}{\partial Y}=\left[\frac{1}{1-\omega}\left(1-\omega H(Y)^{\frac{\theta-1}{\theta}}\right)\right]^{\frac{1}{\theta-1}}\left\{\frac{1}{1-\omega}\left[\left(1-\omega H(Y)^{\frac{\theta-1}{\theta}}\right)-Y \omega H(Y)^{-\frac{1}{\theta}} H^{\prime}(Y)\right]\right\}
$$

Taking the limit of this expression as $Y \rightarrow \infty$ and using the inverse function theorem, we get

$$
\lim _{G \rightarrow \infty} \frac{\partial Y(h, A, G)}{\partial G}=(1-\omega)^{\frac{\theta}{\theta-1}}
$$

and (7) implies that as $G \rightarrow \infty$, the expression in (27) is negative, so the planner problem has a solution.

We now need to show that $(27)$ is larger than zero when $G=0$, so the planner's problem has an interior solution. As $G \rightarrow 0$, we have $\frac{\partial Y}{\partial G} \rightarrow \infty$. Hence it suffices to show that at $G=0$ :

$$
\chi \frac{\partial l_{H}}{\partial Y}+\chi \kappa \frac{\partial k_{H}}{\partial Y}<1
$$

and

$$
\chi \frac{\partial l_{L}}{\partial Y}<1
$$

First assume $h=1$. The wage and the price of capital at $G=0$ are simply $w=\frac{\chi}{\omega} P_{p}$ and $P_{K}=\kappa \frac{\chi}{\omega} P_{p}$ respectively. Therefore, the left-hand side of (28) is just the increase in production costs given an infinitesimal increase in $Y$ times $\omega$, taking everything else constant. Since $\omega<1$ and profits are increasing in $Y$, we know that this is smaller than the infinitesimal increase in revenues after an increase in $Y$, which is given by taking derivatives of $\omega y_{H}(Y, A)^{\frac{\theta-1}{\theta}} Y^{\frac{1}{\theta}}$ with respect to $Y$. Substituting $Y=\omega^{\frac{\theta}{\theta-1}} y_{H}(Y, A)$ in the derivative shows that the increase in revenue is smaller than one (or $1 / \omega$ ) and so is the left-hand side of (28). A similar reasoning applies to (29).

\section{References}

Adam, K. (2007). Optimal monetary policy with imperfect common knowledge, Journal of Monetary Economics 54(2): 267-301.

Angeletos, G.-M. and La'O, J. (2010). Noisy business cycles, NBER Macroeconomics Annual 2009, Vol. 24, University of Chicago Press, pp. 319-378.

Angeletos, G.-M. and La'O, J. (2013). Sentiments, Econometrica 81(2): 739-779.

Angeletos, G.-M. and Pavan, A. (2004). Transparency of information and coordination in economies with investment complementarities, American Economic Review 94(2): 91-98.

Bachmann, R. and Sims, E. R. (2012). Confidence and the transmission of government spending shocks, Journal of Monetary Economics 59(3): 235-249. 
Ball, L. and Romer, D. (1991). Sticky prices as coordination failure, The American Economic Review 81(3): 539-552.

Barro, R. J. (1990). Government spending in a simple model of endogenous growth, Journal of Political Economy $\mathbf{9 8}(5$ pt 2).

Benhabib, J. and Farmer, R. E. (1994). Indeterminacy and increasing returns, Journal of Economic Theory 63(1): 19-41.

Benhabib, J. and Farmer, R. E. (1999). Chapter 6 indeterminacy and sunspots in macroeconomics, Vol. Volume 1, Part A, Elsevier, pp. 387-448.

Blanchard, O. and Perotti, R. (2002). An empirical characterization of the dynamic effects of changes in government spending and taxes on output, The Quarterly Journal of Economics 117(4): 1329-1368.

Bloom, N. (2009). The impact of uncertainty shocks, Econometrica 77(3): 623-685.

Bouakez, H. and Rebei, N. (2007). Why does private consumption rise after a government spending shock?, Canadian Journal of Economics 40(3): 954-979.

Carlsson, H. and Van Damme, E. (1993). Global games and equilibrium selection, Econometrica 61(5): 989-1018.

Chamley, C. (2012). A paradox of thrift in general equilibrium without forward markets, Journal of the European Economic Association 10(6): 1215-1235.

Christiano, L., Eichenbaum, M. and Rebelo, S. (2011). When is the government spending multiplier large?, Journal of Political Economy 119(1): 78-121.

Cochrane, J. H. (2009). Fiscal stimulus, fiscal inflation, or fiscal fallacies?

Cooper, R. and John, A. (1988). Coordinating coordination failures in keynesian models, The Quarterly Journal of Economics 103: 441-463.

Cooper, R. W. and Haltiwanger, J. C. (2006). On the nature of capital adjustment costs, The Review of Economic Studies 73(3): 611-633.

Eggertsson, G. B. (2011). What fiscal policy is effective at zero interest rates?, NBER Macroeconomics Annual 2010, Volume 25, University of Chicago Press, pp. 59-112.

Eggertsson, G. B. and Krugman, P. (2012). Debt, deleveraging, and the liquidity trap: A fisher-minsky-koo approach, The Quarterly Journal of Economics 127(3): 1469-1513.

Erceg, C. and Lindé, J. (2014). Is there a fiscal free lunch in a liquidity trap?, Journal of the European Economic Association 12(1): 73-107. 
Farmer, R. E. and Guo, J.-T. (1994). Real business cycles and the animal spirits hypothesis, Journal of Economic Theory 63(1): 42-72.

Gali, J. (1996). Multiple equilibria in a growth model with monopolistic competition, Economic Theory 8(2): 251-266.

Guimaraes, B. and Machado, C. (2013). Demand expectations and the timing of stimulus policies, CEPR Discussion Paper (9977).

Ilzetzki, E., Mendoza, E. G. and Vegh, C. A. (2013). How big (small?) are fiscal multipliers?, Journal of Monetary Economics 60(2): 239-254.

Kiyotaki, N. (1988). Multiple expectational equilibria under monopolistic competition, The Quarterly Journal of Economics 103(4): 695-713.

Kotlikoff, L. (2012). Krugman's macroeconomic rants, Huffington Post, The Blog, May 14, 2012.

Linnemann, L. and Schabert, A. (2003). Fiscal policy in the new neoclassical synthesis, Journal of Money, Credit and Banking 35: 911-29.

Lorenzoni, G. (2009). A theory of demand shocks, American Economic Review 99(5): 20502084.

Mankiw, G. (2009). Shiller on animal spirits, Greg Mankiw's Blog, January 27, 2009.

Mertens, K. and Ravn, M. (2014). Fiscal policy in an expectations driven liquidity trap, Review of Economic Studies forthcoming.

Morris, S. and Shin, H. (2003). Global games: theory and applications, Advances in Economics and Econometrics (Proceedings of the Eighth World Congress of the Econometric Society). Cambridge University Press, Cambridge.

Morris, S. and Shin, H. S. (1998). Unique equilibrium in a model of self-fulfilling currency attacks, American Economic Review 88(3): 587-597.

Morris, S. and Shin, H. S. (2002). Social value of public information, The American Economic Review 92(5): 1521-1534.

Nimark, K. (2008). Dynamic pricing and imperfect common knowledge, Journal of Monetary Economics 55(2): 365-382.

Ramey, V. A. (2011). Identifying government spending shocks: It's all in the timing, The Quarterly Journal of Economics 126(1): 1-50.

Rotemberg, J. J. and Woodford, M. (1992). Oligopolistic pricing and the effects of aggregate demand on economic activity, Journal of Political Economy 100: 1153-1207. 
Sákovics, J. and Steiner, J. (2012). Who matters in coordination problems?, American Economic Review 102(7): 3439-3461.

Woodford, M. (2002). Imperfect common knowledge and the effects of monetary policy, Aghion, P., R. Frydman, J. Stiglitz, and M. Woodford (eds.) Knowledge, Information and Expectations in Modern Macroeconomics, Princeton University Press.

Woodford, M. (2011). Simple analytics of the government expenditure multiplier, American Economic Journal: Macroeconomics 3(1): 1-35. 